\title{
DETERMINATION OF THE LOCAL SHEAR STRENGTH OF A LAYERED METAL COMPOSITE MATERIAL WITH A DUCTILE INTERLAYER AFTER THERMOCYCLING
}

\author{
S. V. Smirnov ${ }^{1}$, M. V. Myasnikova ${ }^{1}$, A. S. Igumnov ${ }^{2}$ \\ ${ }^{1}$ Institute of Engineering Science, Ural Branch of the Russian Academy of Sciences, 620049, 34 Komsomolskaya st., \\ Ekaterinburg, Russian Federation \\ ${ }^{2}$ Institute of Mathematics and Mechanics, Ural Branch of the Russian Academy of Sciences, 620990, \\ 16 S. Kovalevkoy st., Ekaterinburg, Russian Federation
}

*Corresponding author. E-mail: marina@imach.uran.ru; address for correspondence: ul. Komsomolskaya 34, 620049, Ekaterinburg, Russian Federation. Tel.:+7 (343)375 35 96; fax: +7 (343)374 5330

Using a composition of AMg6 alloy and 12Kh18N10T steel sheets with an intermediate thin layer of the AD1 aluminum alloy as an example, an experimental and theoretical technique is developed for estimating the shear strength of a layered metal composite material with a plastic interlayer. By Vickers indentation results, vertical sides on the boundaries between the composite of layers formed due to interlayer shear have been detected. Dependences relating shear stresses in the interfaces to the indentation depth at different values of the height of the sides have been obtained. The technique has been applied to the examination of this composite after thermocycling and the decrease of the interlayer shear strength of the composite after 25 cycles of the shock change of temperature from $-18{ }^{\circ} \mathrm{C}$ to $+100{ }^{\circ} \mathrm{C}$ has been evaluated.

Keywords: layered metal composite, indentation, shear stress, interlayer shear strength.

DOI: $10.17804 / 2410-9908.2016 .4 .046-056$

\section{References}

1. Gladkovskii S.V., Trunina T.A., Kokovikhin E.A., Kutenyova S.V., Kamantsev I.S., Borodin E.M. Influence study of structural components and production method on formation of structure and properties of layered metal composites. Proizvodstvo prokata, 2014, no. 3, pp. 28-36. (In Russian).

2. Surikova N.S., Panin V.E., Derevyagina L.S., Lutfullin R.Ya., Manzhina E.V., Kruglov A.A., Sarkeeva A.A. Micromechanisms of deformation and fracture in a layered VT6-based material under impact loading. Fizicheskaya Mezomekhanika, 2014, vol. 17, no. 5, pp. 39-50. (In Russian).

3. Ganeeva A.A., Kruglov A.A., Lutfullin R.Ya. Properties of layered composite and prospects for its use. Deformatsiya i razrushenie materialov, 2011, no. 7, pp. 38-40. (In Russian).

4. Maltseva L.A., Tyushlyaeva D.S., Maltseva T.V., Pastukhov M.V., Lozhkin N.N., Inyakin D.V., Marshuk L.A. Metallic laminated composite materials produced by explosion welding: structure, properties, features of interface region structure. Deformatsiya $i$ razrushenie materialov, 2013, no. 4, pp. 19-26. (In Russian).

5. Anoshkin A.N., Zuiko V.Yu., Osokin V.M., Tretyakov A.A., Pisarev P.V. Manufacturing defects in composite flanges: modelling and analysis of influence on static strength. Vestnik PNIPU, 2016. no. 2, pp. 5-21. (In Russian).

6. Grishchenko S.V. Calculation and engineering structure an airplane made of laminated polymeric composite materials taking into account the effects interlaminar. Electronnyi zhurnal "Trudy MAI", 2015, iss. 84. (In Russian). Available at: http://www.mai.ru/science/trudy/published.php?ID=63011 (accessed 27.11.2015).

7. Trykov Yu.P., Belousov V.P., Gurevich L.M., Rogozin V.D., Pisarev S.P., Petrov A.E. Investigating the kinetics of deformation and destruction of explosion-welded four-layer titanium- 
steel composite materials. Deformatsiya i razrushenie materialov, 2007, no. 8, pp. 31-37 (In Russian).

8. Charukhina K.E., Golovanenko S.A., Masterov V.A., Kazakov N.F. Bimetallicheskie soedineniya [Bimetallic Compounds]. Moscow, Metallurgiya Publ., 1970, 288 p. (In Russian).

9. Kozlov I.A., Aleksyuk M.M., Gontarovskii V.P., Lychko I.I. Investigation of the strength of bimetal joints. Strength of Materials, 1975, vol. 7, iss. 2, pp. 178-181. DOI: 10.1007/BF01522143.

10. Patselov A.M, Gladkovskii S.V., Lavrikov R.D., Kamantsev I.S. Fracture strength of laminated composites with alternating of $\mathrm{Ti}-\mathrm{Al} 3 \mathrm{Ti}-\mathrm{Al}-\mathrm{Al} 3 \mathrm{Ti}$ layers under static and cyclic loading. Deformatsiya i razrushenie materialov, 2014, no. 12, pp. 7-11 (In Russian).

11. Chepurko M.I., Ostrenko V.Ya., Kogadeev A.A. Proizvodstvo bimetallicheskikh trub $i$ prutkov [Manufacture of Bimetallic Pipes and Bars]. Moscow, Metallurgiya Publ., 1986, 240 p. (In Russian).

12. Smirnov S.V., Veretennikova I.A., Vichuzhanin D.I. Modeling of delamination in multilayer metals produced by explosive welding under plastic deformation. Computational continuum mechanics, 2014, vol. 7, no. 4, pp. 398-411. DOI: 10.7242/1999-6691/2014.7.4.38. (In Russian).

13. Smirnov S.V., Veretennikova I.A., Kamantsev I.S., Trushina E.B. Fracture boundary study of layer joint of explosion welded bimetal strip "08Cr18Ni10T-steel 10" when rolling. Proizvodstvo prokata, 2014, no. 7, pp. 14-19. (In Russian).

14. Smirnov S.V., Veretennikova I.A. Comparative Evaluation of Metal Damage on the Free Lateral Surface of Single-Layer and Three-Layer Strips under Rolling. Diagnostics, Resource and Mechanics of materials and structures, 2015, iss. 4, pp. 6-15. DOI: 10.17804/24109908.2015.4.006-017. Available at: http://dream-journal.org.

15. Zagirov N.N., Konstantinov I.L., Ivanov E.V. Osnovy raschetov protsessov polucheniya dlinnomernykh metalloisdeliy metodami obrabotki metallov davleniem: ucheb. posobie [Fundamental Calculations for Processes of Long-Length Hardware Production by Metal Forming: educational book]. Krasnoyarsk, IPK SFU Publ., 2011, 152 p. (In Russian).

16. Dragunov Yu.G., Zubchenko A.S., Kashirsky Yu.V., Degtyaryov A.F., Zharov V.V., Koloskov M.M., Orlov A.S., Skorobogatykh V.N. Marochnik stalei $i$ splavov [Steel and Alloy Grade Guide]. Moscow, 2014, 1216 p. (In Russian).

17. Koshkin N.N., Shirkevich M.G. Spravochnik po elementarnoy fizike [Reference Book on Elementary Physics]. Moscow, Nauka Publ., 1976, 256 p. (In Russian). 
Подана в журнал: 11.08 .2016

УДК 620.178.4

DOI: $10.17804 / 2410-9908.2016 .4 .046-056$

\title{
ОПРЕДЕЛЕНИЕ ЛОКАЛЬНОЙ СДВИГОВОЙ ПРОЧНОСТИ СЛОИСТОГО МЕТАЛЛИЧЕСКОГО КОМПОЗИЦИОННОГО МАТЕРИАЛА С ПЛАСТИЧНОЙ ПРОСЛОЙКОЙ ПОСЛЕ ТЕРМОЦИКЛИРОВАНИЯ
}

\author{
С. В. Смирнов ${ }^{1}$, М. В. Мясникова ${ }^{1}$, А. С. Игумнов ${ }^{2}$ \\ ${ }^{I}$ Федеральное государственное бюджетное учреждение науки Институт машиноведения Уральского \\ отделения Российской академии наук, ул. Комсомольская, 34, Екатеринбург, Российская Федераиия \\ ${ }^{2}$ Федеральное государственное бюджетное учреждение науки Институт математики и механики Уральского \\ отделения Российской академии наук, ул. С. Ковалевской, 16, Екатеринбург, Российская Федерация
}

*Ответственный автор. Электронная почта: marina@imach.uran.ru; адрес для переписки: ул. Комсомольская 34, Екатеринбург, Российская Федерация; телефон: +7(343) 375-35-96; факс: +7 (343)374-53-30

На примере соединения листов сплава АМг6 и стали 12Х18Н10Т с промежуточным тонким слоем из алюминиевого сплава АД1 разработана экспериментально-теоретическая методика оценки локальной сдвиговой прочности слоистого металлического композиционного материала с пластичной прослойкой. По результатам вдавливания индентора Виккерса установлено образование ступенек сдвига прослойки на границах соединения слоев. Получены зависимости, связывающие величину напряжений сдвига в плоскостях соединения слоев с глубиной внедрения индентора при разных значениях величины ступеньки. Методика применена для исследования данного соединения после термоциклирования, что позволило сделать количественную оценку снижения межслойной сдвиговой прочности соединения после проведения 25 циклов шокового изменения температуры от -18 до $+100{ }^{\circ} \mathrm{C}$.

Ключевые слова: слоистый металлический композит, индентирование, напряжения сдвига, прочность соединения.

\section{1. Введение}

Определяющее влияние на безопасность эксплуатации изделий из слоистых металлических композиционных материалов (СМКМ) оказывают предельные прочностные характеристики как самих слоев, так и их соединений. Формирование комплекса этих характеристик происходит во время технологических операций изготовления СМКМ [1-4]. Разработка оптимальных режимов получения слоистых композиционных материалов в целом дает возможность обеспечить требуемый уровень конструкционной прочности СМКМ, но не позволяет полностью исключить появление скрытых производственно-технологических дефектов нарушения сплошности материала по поверхностям раздела отдельных слоев (сколов, трещин, пор, карманов, посторонних включений, расслоений и т.п.). Эти типичные локальные повреждения могут оказывать существенное влияние на прочность и жесткость элементов конструкций из СМКМ [5-7]. Кроме того, прочностные свойства слоистых композитов могут изменяться под действием внешних термомеханических воздействий и внутренних структурных изменений, что приводит к образованию эксплуатационных дефектов.

Проблема определения прочностных характеристик материалов, в том числе и СМКМ, обычно успешно решается при проведении стандартных механических испытаний $[2,8-10]$. Сложности возникают в том случае, когда исследуемые слои или детали имеют малые размеры, вследствие чего из них затруднительно, а иногда и невозможно изготовление образцов для проведения типовых испытаний. Поэтому актуальной является разработка методик определения прочностных характеристик материалов на основе методов испытаний, не накладывающих ограничения на размеры исследуемых объектов. Перспективным экспери-

Smirnov S. V. et al. / Determination of the local shear strength of a layered metal composite material with a ductile interlayer after thermocycling. 
ментальным методом в этом смысле является индентирование [11-14], применение которого позволяет определять характеристики прочности в широком диапазоне масштабов от десятков нанометров до десятков миллиметров в зависимости от используемого испытательного оборудования.

Цель настоящей работы - разработка методики, предназначенной для экспертных исследований локальной сдвиговой прочности СМКМ с тонкой пластичной прослойкой и последующее применение ее для оценки деградации межслойной прочности детали, изготовленной из СМКМ и подвергавшейся шоковому термоциклическому воздействию при перемещении ее из области отрицательных температур в кипящую воду. Актуальность решения последней задачи связана с возможностью прогнозирования поведения элементов конструкций из исследуемого СМКМ при резких перепадах температур в результате техногенных и природных воздействий.

\section{2. Материал и методика эксперимента}

В качестве объекта для исследований было выбрано соединение, полученное методом совместной прокатки листов из алюминиевого сплава АМг6 и коррозионно-стойкой стали 12Х18Н10Т с плакирующим покрытием из алюминиевого сплава АД1 с последующим отжигом при температуре $32{ }^{\circ} \mathrm{C}$. Толщина СМКМ составляла 15 мм. Для испытаний вырезали образцы с длиной линии сцепления слоев не менее 20 мм. Исследуемые поверхности образцов подвергали шлифовке и полировке по стандартным методикам. Испытание проводилось на твердомере Akashi и заключалось во внедрении алмазного индентора Виккерса при нагрузках 98, 196, 294 и 490 Н в зону промежуточного алюминиевого плакирующего слоя, когда одна из диагоналей индентора параллельна линии сцепления слоев, а другая - перпендикулярна ${ }^{1}$. Замер диагоналей полученных отпечатков проводили с помощью оптического микроскопа Neophot 21 при 100-кратном увеличении. После испытаний поверхность участка металла вокруг отпечатка исследовали с использованием измерительной системы на базе интерференционного микроскопа NT1100 фирмы Vеeсо, который позволяет получать трехмерное изображение рельефа поверхности с разрешением до 300 нм в плоскости поверхности и менее 1 нм в перпендикулярном направлении.

Упруго-пластическую задачу по внедрению индентора решали методом конечных элементов в программном пакете ANSYS на вычислителе кластерного типа «URAN» ИMM УрО РАН. При этом соединение задавали в виде трех пластин, центральная из которых представляет собой промежуточный плакирующий слой со свойствами алюминиевого сплава АД1 (рис. 1). С учетом симметричности процесса деформации ограничились рассмотрением $1 / 2$ части модели соединения. Граничные условия задавали в перемещениях, исключив перемещение по всем направлениям нижней, торцевой и боковой граней соединения. Для соблюдения условия симметрии процесса плоскость симметрии «закрепляли» от перемещения в направлении оси $z$ (рис. 1). Перемещение индентора задавали из расчета, что после внедрения диагональ отпечатка пирамиды должна перекрыть центральный алюминиевый слой и соответствовать наблюдаемой в экспериментах величине.

\footnotetext{
${ }^{1}$ Испытания проведены Антеноровой Н.П. на оборудовании Центра коллективного пользования ИМАШ УрО PAH.
}

Smirnov S. V. et al. / Determination of the local shear strength of a layered metal composite material with a ductile interlayer after thermocycling. 


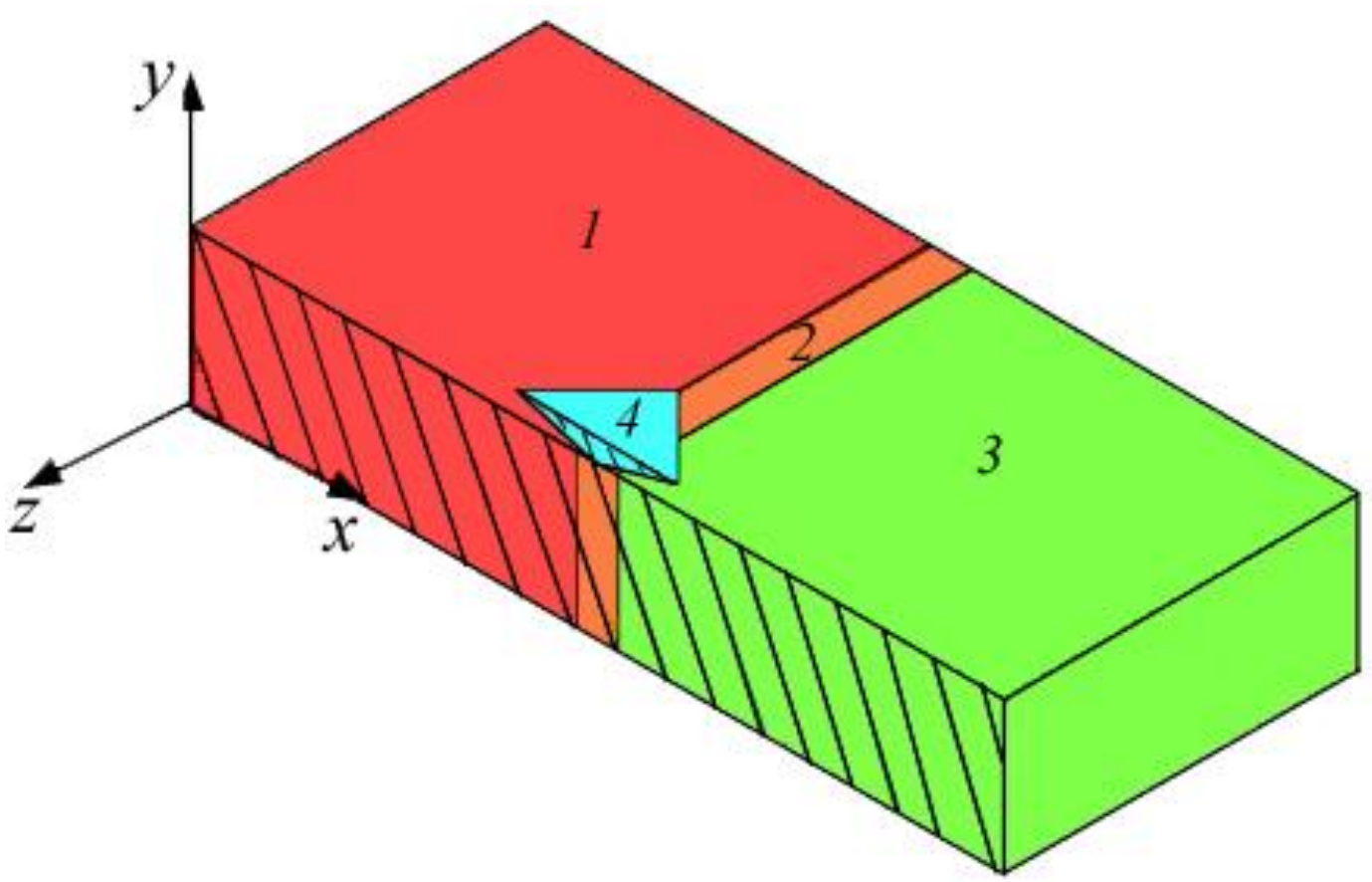

Рис. 1. Геометрическая модель внедрения индентора в промежуточный слой соединения:

1 - пластина из стали марки 12Х18Н10Т; 2 - промежуточный слой из сплава АД1; 3 - пластина из сплава АМг6; 4 - алмазный индентор; (область симметрии заштрихована)

Для определения механических свойств коррозионно-стойкой стали $12 \mathrm{X} 18 \mathrm{H} 10 \mathrm{~T}$ и алюминиевого сплава АМг6 вырезали плоские образцы, которые подвергали одноосному растяжению $^{2}$ на испытательной машине INSTRON 8801 при скорости нагружения 0,1 мм/мин. По результатам испытаний строили кривые деформационного упрочнения, представляющие собой зависимость напряжения течения $\sigma_{\mathrm{s}}$ от степени деформации $\varepsilon$ (рис. 2). Механические свойства алюминиевого сплава АД1 задавали из справочных данных [15].

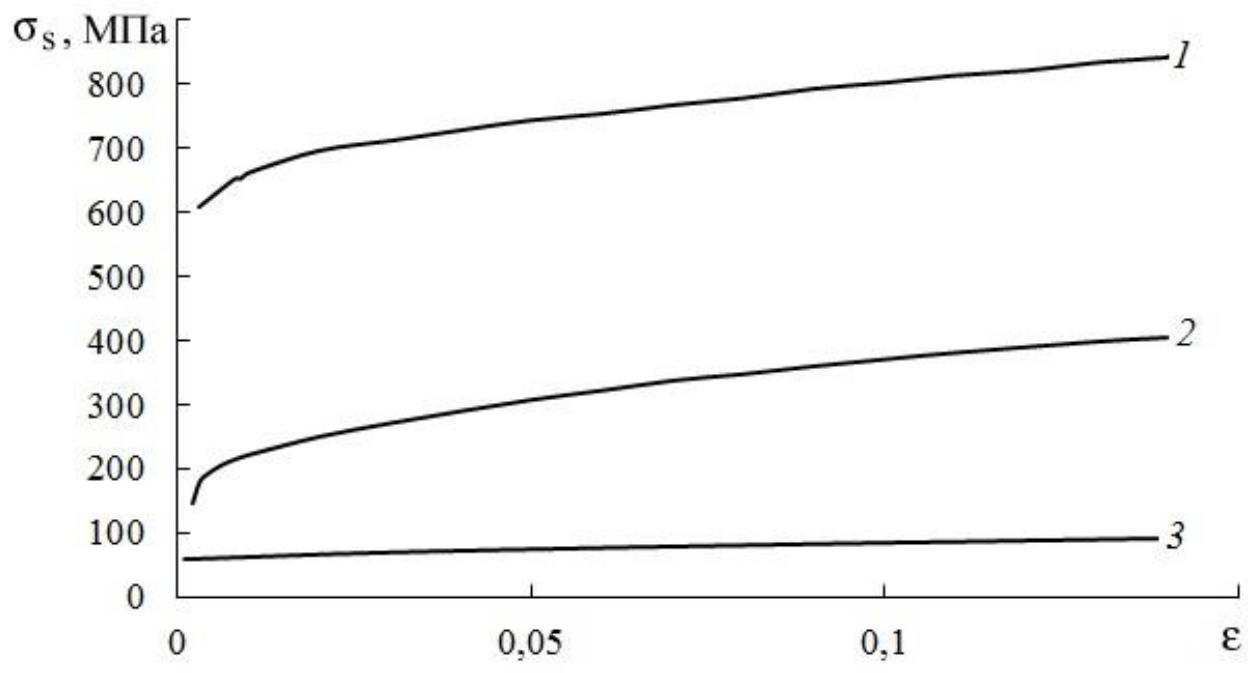

Рис. 2. Кривые деформационного упрочнения стали марки 12X18Н10Т (1); сплава АМг6 (2); сплава АД1 (3)

\footnotetext{
${ }^{2}$ Испытания проведены к.т.н. Вичужаниным Д.И. на оборудовании Центра коллективного пользования ИМАШ УpO PAH
}

Smirnov S. V. et al. / Determination of the local shear strength of a layered metal composite material with a ductile interlayer after thermocycling. 
Упругие свойства принимали равными соответственно: модуль Юнга $E=196$ ГПа и коэффициент Пуассона $v=0,3$ - для стали 12X18H10Т; $E=71$ ГПа и $v=0,3$ - для сплава АМг6; $E=70$ ГПа и $v=0,3$ - для сплава АД1 [16].

При моделировании границы соединения слоев рассматривали как контактные пары, имеющие возможность относительного смещения после нарушения адгезионных связей. В этом случае можно полагать, что полная величина сдвигового напряжения $\tau$, возникающего на границе соединения слоев, складывается из величины адгезионной прочности на сдвиг (предел прочности на сдвиг) $A$ и напряжения трения по Кулону $F$ при скольжении слоев относительно друг друга после расслоения: $\tau=A+F$. В такой интерпретации соотношение между общей высотой выдавленного плакирующего слоя и высотой ступеньки сдвига при заданной глубине вдавливания индентора определяется соотношением величины адгезионной прочности на сдвиг $A$ и напряжения трения $F=\mu p$, где $\mu-$ коэффициент трения по Кулону; $p$ - нормальное давление на границе соединения слоев.

При проведении стандартных испытаний на сдвиг растяжением по мере достижения предельного усилия в плоскости соединения слоев возникает трещина, которая развиваясь приводит к разрушению соединения, причем соответствующее этому моменту напряжение сдвига эквивалентно пределу прочности соединения на сдвиг $A$. Подобные эксперименты были проведены для исследуемого СМКМ и по результатам этих испытаний установлено, что средняя величина адгезионной прочности на сдвиг соединения составляет $A=63$ МПа. Тогда из всех механических характеристик, необходимых для численного моделирования испытаний на вдавливание индентора, имеем всего одну неизвестную величину - коэффициент трения по Кулону $\mu$. Принимая коэффициент трения в качестве варьируемого параметра ставили и решали ряд задач в наиболее вероятном диапазоне изменения $\mu=0,1 \ldots 0,3$ для пары трения металл-металл [17]. При моделировании использовали гексагональные конечные элементы типа SOLID, имеющие 6 степеней свободы. Разбиение конечно-элементной сетки проводили неравномерно, постепенно сгущая количество элементов в области под индентором. Поставленные задачи решали с использованием процедуры Ньютона-Рафсона и фронтального прямого решателя.

\section{3. Результаты и их обсуждение}

В результате проведенных исследований было установлено, что деформационный рельеф на поверхности шлифа, видимый средствами световой микроскопии, образуется за счет выдавливания вверх части металла плакирующего слоя. Это связано с тем, что плакирующий слой, состоящий из технически чистого алюминия, имеет сопротивление деформации меньшее, чем соединяемые слои композита и поэтому металлу слоя, выдавливаемому индентором, энергетически выгодней смещаться вверх в сторону свободной поверхности, а не раздвигать более прочные слои стали и сплава АМг6. При этом профиль выдавленного участка имеет специфическую конфигурацию, представляющую собой дугообразный купол с характерными вертикальными ступеньками на границах слоя и соединяемых материалов.

Высоту ступенек $h_{c}$ (рис. 3) измеряли с помощью оптического профилометрапрофилографа NT1100 и полагали, что сама высота ступеньки при фиксированной глубине внедрения индентора зависит от наличия возможности относительного смещения слоев композита после нарушения адгезионных связей, хотя и не определяет непосредственно предел прочности на сдвиг. Опытные данные, полученные таким образом для трех образцов СМКМ, аппроксимировали в виде графических зависимостей высоты ступеньки от глубины внедрения индентора для каждой границы соединения слоев СМКМ (рис. 4). 


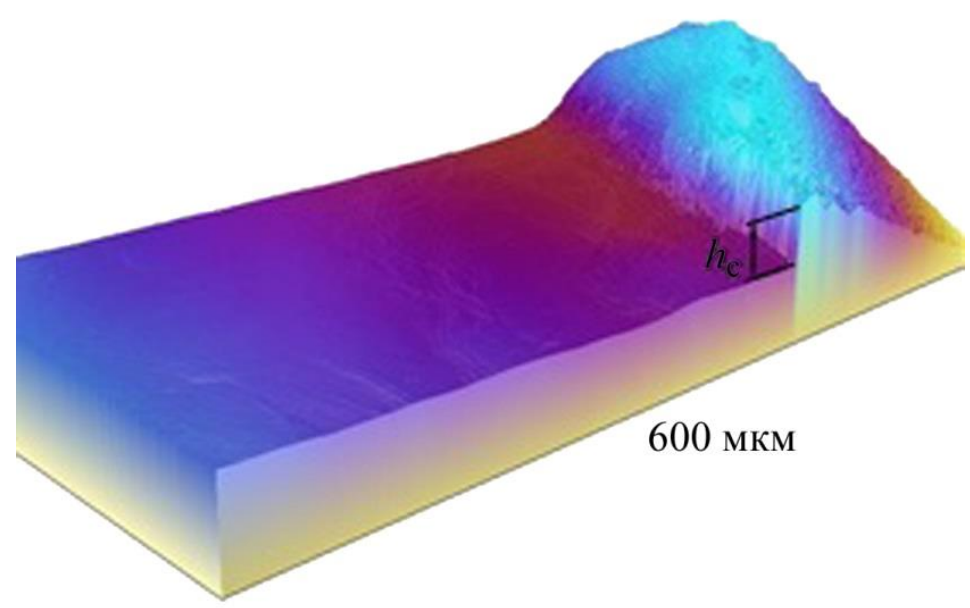

Рис. 3. Профиль участка около отпечатка индентора на границе соединения сплава АМг6 с плакирующим слоем с характерной вертикальной ступенькой, нагрузка $490 \mathrm{H}$

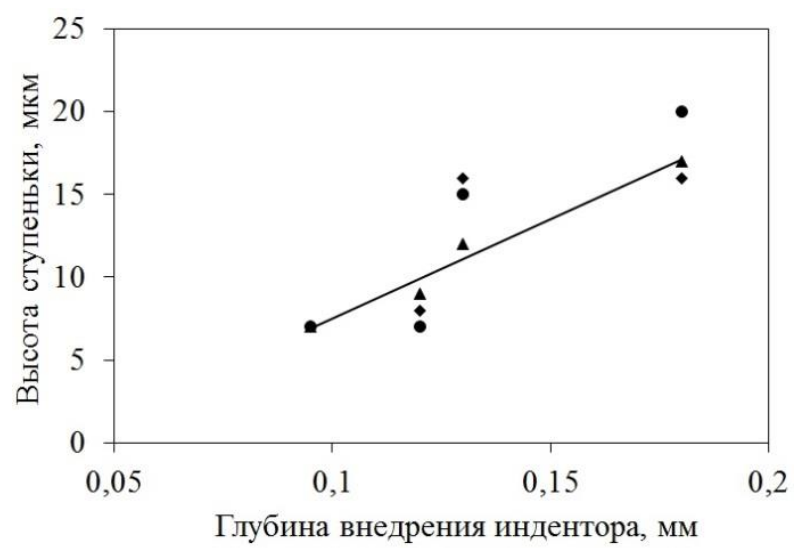

$a$

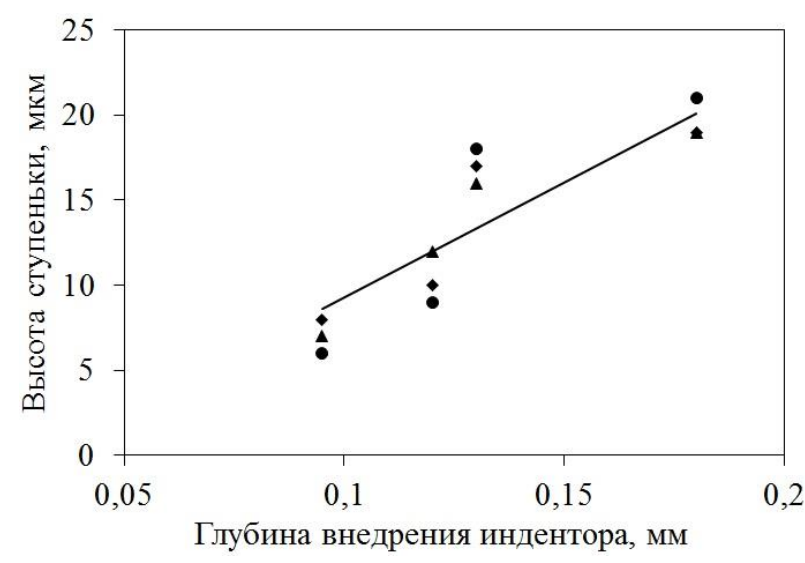

$\sigma$

Рис. 4. Экспериментальные зависимости высоты ступеньки от глубины внедрения индентора на границе соединения: $a$ - плакирующего слоя и стали $12 \mathrm{X} 18 \mathrm{H} 10 \mathrm{~T}$; б - на границе соединения плакирующего слоя и сплава АМг6

Для количественной оценки напряжений, возникающих в плоскостях соединения слоев СМКМ при вдавливании индентора, использовали результаты конечно-элементного моделирования в виде совокупности расчетных зависимостей высоты ступеньки на выдавленном промежуточном пластичном слое от глубины вдавливания индентора для каждого значения $\mu$. Сравнивая экспериментальные и расчетные данные по величине ступенек, подобрали значения коэффициентов трения на границах соединения слоев: $\mu=0,25$ на границе «плакирующий слой - сталь 12X18Н10Т»; $\mu=0,15$ на границе «плакирующий слой - сплав АМг6». Поскольку локальная адгезионная прочность сцепления слоев соединения в ряде случаев может значительно отличаться от сдвиговой прочности всего соединения в целом осуществили численное моделирование процесса внедрения индентора в промежуточный алюминиевый слой при выбранных значениях $\mu$, варьируя теперь уже величину $A$ на границах раздела слоев в диапазоне изменения $A=10 \ldots 100$ МПа. В результате выполненных расчетов были построены диаграммы зависимости высоты ступеньки на границе раздела слоев СМКМ от глубины внедрения индентора при разных значениях локальной адгезионной сдвиговой прочности (рис. 5 и 6). 


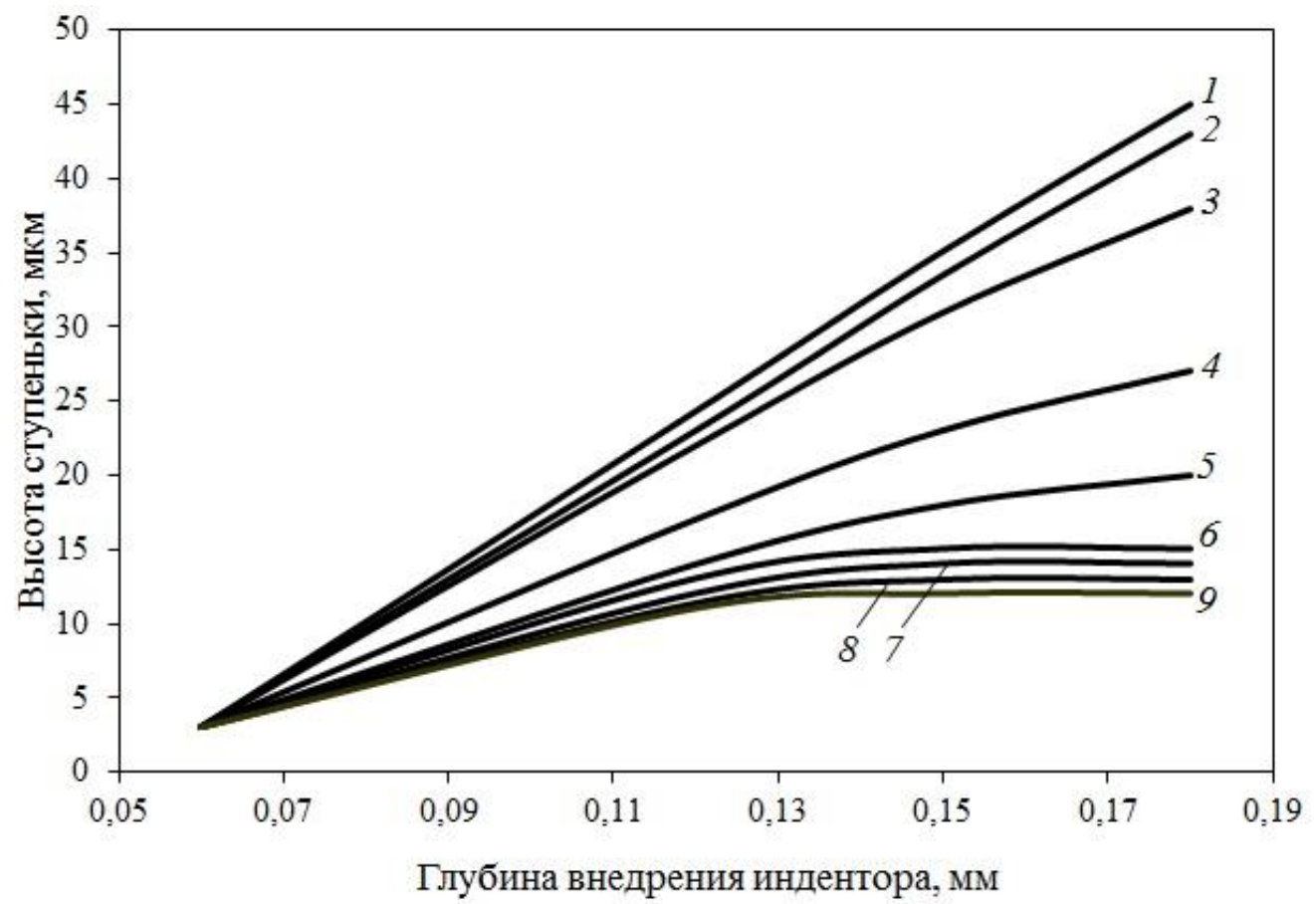

Рис. 5. Влияние глубины внедрения индентора и сдвиговой межслойной прочности на высоту ступеньки на границе соединения плакирующего слоя и стали $12 \mathrm{X} 18 \mathrm{H} 10 \mathrm{~T}: 1-\mathrm{A}=10$ МПа; 2 - 20 МПа; 3 - 30 МПа; 4 - 40 МПа; 5 - 50 МПа; 6 - 60 МПа; 7 - 70 МПа; $8-80 \div 90 \mathrm{MПа} ; 9-100 \mathrm{MПа}$

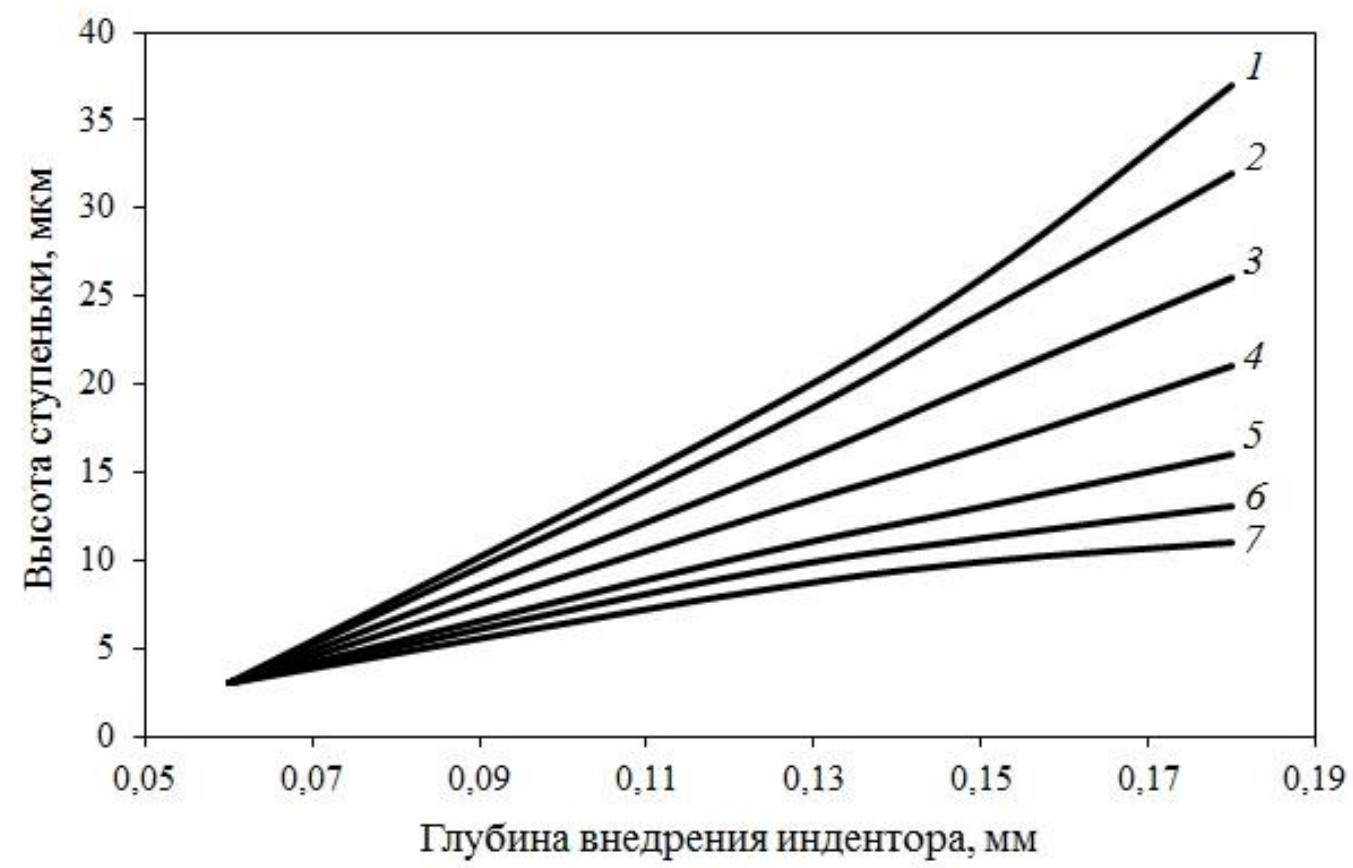

Рис. 6. Влияние глубины внедрения индентора и сдвиговой межслойной прочности на высоту ступеньки на границе соединения плакирующего слоя и сплава АМг6: 1 - А = 10 МПа; 2 - 20 МПа; 3 - 30 МПа; 4 - 40 МПа; 5 - 50 МПа; 6 - 60 МПа; 7 - > 70 МПа

С использованием построенных диаграмм можно осуществлять оценку локальной межслойной адгезионной прочности на сдвиг $A$ данного СМКМ, в том числе и после различных термомеханических воздействий при вполне логичном допущении, что коэффициент $\mu$ не изменяется. Для этого после проведения испытаний на индентирование необходимо 
произвести замеры высоты ступеньки на каждой границе соединения слоев при определенной глубине внедрения индентора и по их значениям определить величину локальной межслойной адгезионной прочности на сдвиг, пользуясь диаграммами на рис. 5 и 6.

Описанная выше методика была применена для исследования влияния шокового термоциклирования на межслойную сдвиговую прочность конструктивного элемента «штуцер» соединения топливопровода с топливным баком реактивного двигателя, изготовленного из того же СМКМ, что и рассмотренный выше. Максимальный габаритный размер штуцера 25 мм, поэтому из него не могли быть изготовлены образцы для проведения стандартных испытаний на растяжение. Исследовали межслойную прочность материала штуцера в исходном состоянии и после шокового термоциклирования, заключающегося в охлаждении штуцера в холодильной камере до $-18{ }^{\circ} \mathrm{C}$ и последующем помещении в воду с температурой $100{ }^{\circ} \mathrm{C}$. Всего было осуществлено 25 подобных циклов.

Изучение участков металла вокруг отпечатков после индентирования при нагрузках $490 \mathrm{H}$ и $294 \mathrm{H}$ (глубина внедрения индентора при этом составляет 143 мкм и 121 мкм соответственно) показало, что в исходном состоянии СМКМ на границах «промежуточный слой - сталь 12Х18Н10Т» и «промежуточный слой - сплав АМг6» вертикальных ступенек, видимых средствами световой микроскопии, не образуется. Это позволяет сделать вывод, что локальная межслойная прочность на сдвиг СМКМ в исходном состоянии больше, чем максимальное значение $A=100 \mathrm{MПа,} \mathrm{допустимо} \mathrm{возможное} \mathrm{для} \mathrm{определения} \mathrm{по} \mathrm{разработанной}$ методике. Испытания на индентирование, проведенные после термоциклирования, показали, что при нагрузке на индентор 490 Н (глубина внедрения 171 мкм) на границе «промежуточный слой - сталь 12Х18Н10Т» образуется характерная ступенька высотой 7 мкм, а на границе «промежуточный слой - сплав АМг6» аналогичная ступенька высотой 13 мкм. При нагрузке на индентор 294 Н (глубина внедрения 153 мкм) вертикальные ступеньки на границах соединения слоев СМКМ также фиксируются и составляют соответственно 6 мкм на границе «промежуточный слой - сталь $12 \mathrm{X} 18 \mathrm{H} 10 \mathrm{~T}$ » и 12 мкм на границе «промежуточный слой - сплав АМг6». Локальная межслойная сдвиговая прочность после термоциклирования уменьшается по сравнению с исходным состоянием и составляет примерно 55 МПа на границе «промежуточный слой - сплав АМг6», но остается более 100 МПа на границе «промежуточный слой - сталь 12Х18Н10Т».

Таким образом, в результате проведенных исследований было установлено, что проведенное шоковое термоциклирование снижает межслойную сдвиговую прочность материала штуцера. Вероятной причиной этого явления может быть возникновение дефектов сплошности на границах соединения слоев СМКМ вследствие несовместимости термических деформаций, обусловленной различием коэффициентов теплового расширения материалов слоев СМКМ, из которого изготовлен штуцер.

\section{4. Заключение}

Экспериментально установлено, что в результате внедрения индентора Виккерса в зону пластичной прослойки СМКМ, полученного методом совместной прокатки листов сплава АМг6 и стали 12Х18Н10Т с промежуточным слоем из алюминиевого сплава АД1, происходит выдавливание вверх участка алюминиевой прослойки с образованием характерных вертикальных ступенек на границах соединяемых участков. Наличие такого специфического профиля выдавленного участка алюминиевого слоя позволило разработать экспериментально-теоретическую методику для исследований локальной межслойной сдвиговой прочности соединения слоев СМКМ. Особенность данной методики заключается в том, что полные сдвиговые напряжения на границах соединения слоев СМКМ представляются в виде суммы двух составляющих: адгезионной составляющей и составляющей сил трения скольжения по Кулону после нарушения адгезионных связей. В отличие от известных методик индентирования, применяемых для определения прочности на отрыв в соединениях материалов, име-

Smirnov S. V. et al. / Determination of the local shear strength of a layered metal composite material with a ductile interlayer after thermocycling. 
ющих близкий уровень прочности, разработанная методика предназначена для оценки межслойной прочности на сдвиг СМКМ с тонкими мягкими прослойками. Построенные зависимости высоты ступеньки на границе соединения слоев СМКМ от глубины внедрения индентора при разных значениях адгезионной сдвиговой прочности позволяют дать количественную оценку локальной межслойной прочности на сдвиг исследуемого СМКМ, в том числе и после различных термомеханических воздействий. С использованием разработанной методики проведено исследование влияния шокового термоциклирования в диапазоне температур $-18 \ldots+100{ }^{\circ} \mathrm{C}$ на деградацию межслойной сдвиговой прочности штуцера в топливной системе реактивного двигателя, изготовленного из СМКМ конструкции «сплав АМг6 + прослойка из сплава АД1 + сталь 12Х18Н10Т». Полученные результаты свидетельствуют о возможности использования принципов, заложенных в данную методику, для разработки аналогичных методик применительно к другим СМКМ и герметизирующим прослойкам для оценки влияния на их прочностные свойства внешних воздействующих факторов.

\section{Благодарность}

Работа выполнена в рамках Комплексной программы УрО РАН, проект № 15-15-1-52.

\section{Литература}

1. Исследование влияния конструктивных элементов и способа изготовления на формирование структуры и свойств слоистых металлокомпозитов / С. В. Гладковский, Т. А. Трунина, Е. А. Коковихин, С. В. Кутенёва, И. С. Каманцев, Е. М. Бородин // Производство проката. - 2014. - № 3. - С. 28-36.

2. Микромеханизмы деформации и разрушения слоистого материала из титанового сплава ВТ6 при ударном нагружении / Н. С. Сурикова, В. Е. Панин, Л. С. Деревягина, Р. Я. Лутфуллин, Э. В. Манжина, А. А. Круглов, А. А. Саркеева // Физическая мезомеханика. - 2014. - T. 17. - № 5. - С. 39-50.

3. Ганеева А. А., Круглов А. А., Лутфуллин Р. Я. Свойства слоистого композиционного материала и перспективы его использования // Деформация и разрушение материалов. 2011. - № 7. - С. 38-40.

4. Металлические слоистые композиционные материалы, получаемые сваркой взрывом: структура, свойства, особенности строения переходной зоны / Л. А. Мальцева, Д. С. Тюшляева, Т. В. Мальцева, М. В. Пастухов, Н. Н. Ложкин, Д. В. Инякин, Л. А. Маршук // Деформация и разрушение материалов. - 2013. - № 4. - С. 19-26.

5. Моделирование технологических дефектов и оценка их влияния на статическую прочность композитных фланцев / А. Н. Аношкин, В. Ю. Зуйков, В. М. Осокин, А. А. Третьяков, П. В. Писарев // Вестник ПНИПУ. - 2016. - № 2. - С. 5-21.

6. Грищенко С. В. Расчет и проектирование изделий конструкции самолета из слоистых композитов с учетом межслоевых дефектов [Электронный ресурс] // Электронный журнал

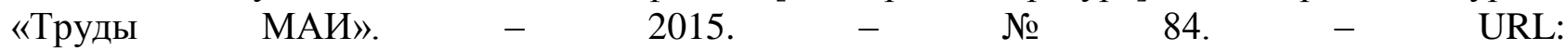
http://www.mai.ru/science/trudy/published.php?ID=63011 (дата обращения: 27.11.2015).

7. Исследование кинетики деформации и разрушения сваренных взрывом четырехслойных титаностальных композитов / Ю. П. Трыков, В. П. Белоусов, Л. М. Гуревич, В. Д. Рогозин, С. П. Писарев, А. Э. Петров // Деформация и разрушение материалов. - 2007. № 8. - С. 31-37.

8. Биметаллические соединения / К. Е. Чарухина, С. А. Голованенко, В. А. Мастеров, Н. Ф. Казаков. - М. : Металлургия, 1970. - 288 с.

9. Investigation of the strength of bimetal joints / I. A. Kozlov, M. M. Aleksyuk, V. P. Gontarovskii, I. I. Lychko // Strength of Materials. - 1975. - Vol. 7, iss. 2. - P. 178-181. DOI: $10.1007 / \mathrm{BF} 01522143$. 
10. Трещиностойкость слоистых композитов с чередованием слоев Ti-Al3Ti-Al-Al3Ti в условиях статического и циклического нагружения / А. М. Пацелов, С. В. Гладковский, Р. Д. Лавриков, И. С. Каманцев // Деформация и разрушение материалов. - 2014. - № 12. С. 7-11.

11. Чепурко М. И., Остренко В. Я., Когадеев А. А. Производство биметаллических труб и прутков. - М. : Металлургия, 1986. - 240 с.

12. Смирнов С. В., Веретенникова И. А., Вичужанин Д. И. Моделирование расслоения при пластической деформации биметаллического материала, полученного сваркой взрывом // Вычислительная механика сплошных сред. - 2014. - Т. 7, № 4. - С. 398-411. DOI: 10.7242/1999-6691/2014.7.4.38.

13. Исследование разрушения границы соединения слоев у полученной сваркой взрывом биметаллической полосы «08Х18Н10Т-Сталь 10» при прокатке / С. В. Смирнов, И. А. Веретенникова, И. С. Каманцев, Е. Б. Трушина // Производство проката. - 2014. - № 7. - C. 14-19.

14. Smirnov S. V., Veretennikova I. A. Comparative Evaluation of Metal Damage on the Free Lateral Surface of Single-Layer and Three-Layer Strips under Rolling [Электронный ресурс] // Diagnostics, Resource and Mechanics of materials and structures. - 2015. - Iss. 4. - P. 6-15. DOI: 10.17804/2410-9908.2015.4.006-017. - URL: http://dream-journal.org.

15. Загиров Н. Н., Константинов И. Л., Иванов Е. В. Основы расчетов процессов получения длинномерных металлоизделий методами обработки металлов давлением : учеб. пособие. - Красноярск : ИПК СФУ, 2011. - 152 с.

16. Марочник сталей и сплавов / Ю. Г. Драгунов, А. С. Зубченко, Ю. В. Каширский, А. Ф. Дегтярев, В. В. Жаров, М. М. Колосков, А. С. Орлов, В. Н. Скоробогатых / под общ. ред. Ю. Г. Драгунова и А. С. Зубченко. - 4-е изд., перераб. и доп. - М., 2014. - 1216 с. ISBN 978-5-94275-528-9.

17. Кошкин Н. Н., Ширкевич М. Г. Справочник по элементарной физике. - М. : Наука, 1976. $-256 \mathrm{c}$. 